\title{
Forwarding Arts Therapy in South East Asia
}

\section{在东南亚推动艺术治疗的发展}

\author{
Joanne Kelly', Amanda Levey² and Ronald Lay ${ }^{3}$ \\ ${ }^{1}$ The Australian and New Zealand Arts Therapy \\ Association, Australia \\ ${ }^{2}$ Whitecliffe College of Arts and Design, New Zealand \\ ${ }^{3}$ LASALLE College of the Arts, Singapore
}

\begin{abstract}
Over the past ten years, the profession of arts therapy has come a long way in South East Asia. As the first and truly only international professional association in the Asia-Pacific region, the Australian and New Zealand Arts Therapy Association (ANZATA) is now firmly positioned as a professional community which contributes effectively towards the development of the arts therapies. In all countries where arts therapy has evolved, there have been significant challenges inherent in establishing and developing a credible professional identity. Such identity and recognition applies not only to how we view ourselves but also, importantly, to how we are viewed by the public, by other professions and by governments. A healthily developing professional association is a vital component of any emerging profession, and grows in tandem with a dynamic and developing practice, with rigorous standards of training within solid theoretical frameworks, with an adherence to ethical guidelines, and with an evolving research culture. As arts therapy gains momentum across the globe, specifically within this geographical area, the profession is coming of age providing exciting opportunities for interdisciplinary collaborations where differences and diversity are acknowledged, embraced and integrated. The link that connects us all is the healing power of the creative process and the recognition of its vital importance to our lives and wellbeing.
\end{abstract}

Keywords: arts therapy, Australia, New Zealand, Singapore, development of profession.

\section{摘要}

在过去十年里，艺术治疗作为职业在东南亚取得了很大的发展。新澳艺术治疗协会 ( ANZATA ) 作为亚太地区第一个唯一的国际专业协会已经有了坚实的立足之地，并以 职业团体的身份出色地贡献于艺术治疗的发展。在艺术治疗有所发展的国家里，为它建 立和发展一个可信的职业身份极具挑战性。这种身份和认可不仅作用于我们对自身的认 定，也影响着广大群众、其他职业以及政府对我们的认定。对一个萌芽状态下的职业， 一个强大而且持续发展的职业协会必不可缺。它的发展伴随着这个职业自身的发展、基 于扎实理论框架的严格培训标准、对伦理道德方针的遵循，以及不断进化的研究氛围。 随着艺术治疗在全世界的推广，它在亚太地区内逐渐变得成熟，给跨学科的合作提供了 激动人心的机会，使得差异和多元化被承认、接受、结合。创造的过程所带来的疗愈和 对我们生活和安乐中创造过程的重视是连接我们所有人的桥梁。

\section{关键词: 艺术治疗, 澳大利亚, 新西兰, 新加坡, 职业发展}




\section{Introduction}

In the last ten years, interest in arts therapy has grown and developed extensively in South East Asia. This paper considers the growth and development of arts therapy particularly as it relates to Australia, New Zealand and Singapore. It also addresses how the Australian and New Zealand Arts Therapy Association (ANZATA) can contribute towards the development of arts therapy as a recognised profession in South East Asia. In all three of these countries - as with all other countries where arts therapy is evolving - there have been significant struggles in order to both establish and develop a credible professional identity. Such identity (and recognition of that identity) applies not only to a collective view of ourselves, but also, importantly, to how we are viewed by both the community at large and by other professions.

The role of the arts in the process of healing has been recognized for millennia. In 20 th century Western culture, many aspects of the arts are once again being applied in a healing capacity, focusing on wellbeing, health and education. There have been both challenges and opportunities as professionally trained arts therapists seek both an understanding of and acceptance by others about who they are and what they do. As arts therapy gains momentum across the globe - and especially in this region - there is a sense that the profession is now coming of age; it is providing exciting opportunities for interdisciplinary collaborations while acknowledging differences and diversity. These opportunities involve developing culturally appropriate and perhaps region-specific theoretical frameworks in both training and practice, interdisciplinary co-operation and collaboration in research, and the building of deepening connections and partnerships with other professional associations, organizations and institutions. The link that connects us all in these four areas is the healing power of the creative process and its vital importance to our lives and wellbeing.

\section{The First Peoples}

Although there remains some debate (Cane, 2013; Dorey, 2011), indigenous Australians are generally understood to have travelled by sea from South-east Asia, arriving on the Australian mainland between 40,000 and 70,000 years ago. Their artistic, musical and spiritual traditions are amongst the longest surviving examples of such traditions in human history. Rock art in the Northern Territory, for example, is thought to be up to 20,000 years old. Indigenous New Zealanders - the Maori - originated from eastern Polynesia and used their sophisticated navigational knowledge and practices to travel to and settle in New Zealand approximately 1,000 years ago. They, too, brought with them a rich culture of musical, artistic and spiritual traditions. In Singapore, indigenous Malays are known for their artistic and musical cultural traditions. In contemporary society, these indigenous artistic and spiritual traditions continue to influence current Asian and Pacific cultures - including models of health and wellbeing. In turn, such traditions are increasingly acknowledged and valued by Australian, New Zealand and Singaporean arts therapists.

All three countries were colonised by Britain in the $18^{\text {th }}$ and $19^{\text {th }}$ centuries. All are still members of the Commonwealth Countries. The population of Australia is currently 
about 23 million, with most people living in cities on the coastal fringes of the continent. While still constitutionally linked to Britain, subsequent waves of immigration from all over the world have helped to shape Australia into the rich multicultural society that it is today. Indigenous Australians were nomadic and were comprised of distinct peoples and languages. Colonisation had a devastating impact on the Aboriginal people who, according to Westwood and Linnell (2011, p. 2), still remain "profoundly disadvantaged in terms of their economic, social and health status".

Covering a much smaller geographical area, New Zealand consists of narrow islands surrounded by sea. The current population is about four and a half million. Although also colonised by the British, there was a relatively large and assertive indigenous Maori population who, rather than being nomadic, had a strong tradition of land occupation and agriculture. Although it has also been significantly affected by colonisation, New Zealand has had a history of indigenous rights that contrasts somewhat with that of Australia - due largely to the Treaty of Waitangi (History Group of the New Zealand Ministry for Culture and Heritage, 2015), which was a partnership agreement between the British Crown and the Maori people. In a growth of population similar to that of Australia, many cultures have migrated to New Zealand and settled there - including significant numbers of migrants from Asia. There has always been a close relationship both economically and socially - between Australia and New Zealand.

As a trading nation, the island of Singapore has a population of approximately five and a half million people and is known to be one of the most economically successful countries in the world (CIA, 2015). Under a stable political environment, Singapore has developed high standards of health care and educational provision and holds progressive policies on environmental sustainability. According to Aun Long and Tan (2012), both its multiculturalism and cosmopolitan diversity have contributed significantly to its global success in a contemporary world. In addition to its the rich Malay heritage, additional traditions, customs and rituals from both the Chinese and Indian cultures, have influenced and affected significant arts-related aspects of the city-state itself.

\section{The Development of the Profession of Arts Therapy}

Compared to the growth of arts therapy as a profession in Europe and North America, the emergence of arts therapy as a recognised career has been a relatively recent development in Australia, New Zealand and Singapore. Researchers in the field have charted the development of the profession in Australia and New Zealand (Westwood, 2012; Westwood \& Linnell, 2011; Woodcock, 2011) observing that early arts therapy practitioners and educators were trained in the United Kingdom (UK), Europe, the United States of America (US) and Canada; historically, the profession tended to look to these countries for their theoretical base and therapeutic practices. Essame indicates further growth and development - commenting that the melding of Eastern and Western values balances each other in Singaporean arts therapy (2012, p. 94).

For arts therapists living in and practicing in this region, it can be argued that the profession is based on an ancient and universal knowing shared by all indigenous cultures and that the arts and creativity are inseparable from our health and wellbeing. In all ancient societies, the arts were seen to be integral to the expression and healing of 
individuals and the community and were fundamental to daily life as well as to the creation of ceremony and ritual (A. Halprin, 2000; D. Halprin, 2003; Kaplan, 2005; Payne, 1992). American arts therapist, McNiff (2004), notes that the experiential elements of traditional healing engage the body, mind and spirit and that ceremony, ritual and art are all essential to the process. According to Kim (2012) arts therapy therefore creates a powerful bridge between Western and non-Western models of wellbeing.

Kalmanowitz, Potash and Chan (2012, p.29) claim that although colonisation in Asia caused a "degree of devaluing" of traditional models and practices of health and ritual, "...the ancient use of the arts in healing were not altogether lost". This is paralleled in the cultures of indigenous Australians, the Maori and Pacific peoples (Agee, McIntosh, Culbertson, \& Makasiale, 2013; Durie, 2003; Gilroy \& Hanna, 1998; Linnell, 2009; Turner, 2006; Webber, 2013). More recently, arts therapists in Australia and New Zealand have been increasingly looking to their own indigenous cultures and beyond for alternative models of health and wellbeing. Kalmanowitz, Potash and Chan (2012) have readily identified the enormous influence of Asian ideas on Western thought with the explosion of interest in mindfulness and meditation and such physical practices as yoga and tai chi. This establishing of stronger links with Asia and the Pacific - the source of many of our indigenous populations - represents a necessary and important connectedness and perhaps a re-connectedness between traditional wisdom and contemporary thought and understanding.

\section{The Evolution of ANZATA}

The evolution of ANZATA (as it is known today) had humble beginnings. In 1984 according to American art therapist Bobbi Stoll - there were only two qualified art therapists in Australia (2005, p. 176). When the Australian National Art Therapy Association (ANATA) was formed in 1987, most of its small membership had trained overseas - mostly in the United Kingdom, the United States or Canada, - with diverse training methodologies and approaches to the subject area (Westwood, 2012). The first masters-level art therapy training courses in Australia (originally four in number and based on training standards equivalent to the highest international standard) began in the early 1990s and graduates of these programs became eligible to join the association as professional members. In 2005, graduates of the only masters-level training program in New Zealand were accepted as professional members and so the name of the organization was changed to The Australian and New Zealand Art Therapy Association (ANZATA).

The inclusion of New Zealand in ANZATA was significant for several reasons: as in Australia, the early arts therapy educators in New Zealand were trained overseas leading them to bring with them different theoretical models and approaches. However (perhaps due to a stronger awareness of their indigenous culture) there was a growing consciousness among New Zealand art therapists that it was important they develop a model of arts therapy that was responsive to the local context rather than blindly apply methods and models that were not linked to geographical and cultural locations (see for example, Woodcock, 2007). Practitioners advocated the development of close ties with the Pacific region as well as with Australia. The need to develop culturally-sensitive 
practices that were responsive to both the Maori worldview and that of other migrants has, consequently, affected the development of arts therapy training and practice within this region (Woodcock, 2011). Maori models of health and their view of the arts as being integrated into (and therefore inseparable from) other social and cultural forms have influenced the relationships between all the arts modalities (visual art, dance/movement, drama) within the arts therapy program in New Zealand (Westwood, 2012, p. 23). This, in turn, has influenced the development of ANZATA both in terms of its cultural sensitivity and its acceptance and inclusion of other arts therapy modalities.

Subsequently, in 2007, professional membership of the Association was extended to appropriately qualified arts therapists working in creative modalities other than visual art; these modalities included dance/movement therapy and drama therapy. Australia and New Zealand already possessed well-established music therapy associations; this discipline has remained quite separate from the other creative therapies. The graduates of an Australian masters-level drama therapy training and multi-modal courses in New Zealand and Australia or equivalent overseas trained practitioners are now eligible to become professional members. To reflect this addition of modalities, the title of the Association is now the 'Australian and New Zealand Arts Therapy Association' with the 's' added to the word 'arts' to indicate that the association represents therapists working in many creative modalities.

ANZATA's involvement in Singapore is more recent still. In the spirit of arts therapy - and with the belief that the arts are vital to one's well-being and to the growth and maintenance of healthy communities - Brother Joseph McNally founded LASALLE College of the Arts in Singapore in 1984. As the college developed, it introduced its first postgraduate masters training program in art therapy in 2006. By 2008, graduates of the program (along with other local art therapists) established the Art Therapists'Association Singapore (ATAS) which was the first local professional art therapy association.

Until August 2012, the Open University (OU) in the UK validated the masters program in Singapore. Since 2012, however, it has been validated by Goldsmiths College, University of London. In 2009, graduates of the art therapy program in Singapore were approved for professional membership by ANZATA. The Association currently has a thriving and ever-increasing professional membership in Singapore and is now actively considering how to reflect Singapore in the name of the Association. Additionally, there are also other organizations and countries in our region that have expressed interest in aligning with ANZATA - with memoranda of understanding being signed by two other organizations.

There have been two significant factors that have presented both challenges and advantages for ANZATA: first, that arts therapies in our region have developed later in comparison to other Western countries and second, that our relatively small populations are spread over an immense geographical area. As stated previously, those art and arts therapists who first practiced in Australia and New Zealand (and those who set up the first training programs) came to understand that they needed to integrate many different theoretical, ethical and clinical approaches into their work - expanding upon what they had learned in the various countries where they had trained and practiced (Coulter, 2006). Acknowledging, embracing and creatively overcoming those challenges has provided the training programs in our region with integrative and eclectic approaches 
based upon psychodynamic, humanistic and post-modern principles and has ensure that trainees become aware of a multitude of approaches, traditions and paradigms. According to Westwood (2012), locally trained graduates are now becoming experienced enough to return to teach on training courses; this means that each program has developed its own distinct culture and each region has an arts therapy community that is both diverse and dynamic.

Westwood's PhD research (based on arts therapy training in Australia) also notes that UK-trained educators favored an experiential psychodynamic approach, whereas some US approaches "prioritized the development of research and a more didactic view related to the medical sciences and directive approaches" $(2012$, p. 18). Other educators have included differing psychological frameworks such as humanism and, more recently, post-modern models and frameworks. In the mental health systems of both New Zealand and Australia, the Western medical model has favored psychological approaches which are cognitive, behavioral and psycho-educational (Westwood and Linnell, 2011). Westwood explains that it has been challenging to establish arts therapy as a legitimate psychological intervention in its own right as the traditionally psychodynamic approaches of the arts therapies have often been marginalized and, more often than not, have operated outside of the mainstream health systems.

In Australia, New Zealand and Singapore, as in many other countries, there has also been the parallel growth and development of many differing organizations aiming to represent those working in this area. These organizations have ranged from relatively informal networking associations to more formal professional bodies such as ANZATA and the Australian Music Therapy Association. As Australia, New Zealand and Singapore have relatively small populations, this means that it is difficult for each country to sustain its own art or arts therapy association or to have separate associations for each arts modality. Subsequently, there has been a strong motivation to join together - along both geographical and creative modality lines - leading to the necessity for clear communication and mutual understanding.

\section{ANZATA Today}

Apart from music therapy, ANZATA is the main professional association for arts therapists in Australia, New Zealand and Singapore. There are, however, other relevant associations that represent the broader field of psychotherapies and counselling professions, and/or provide professional membership for graduates from courses that are not currently approved by ANZATA (Westwood \& Linnell, 2011). Here, our limited size has had a positive effect; there have been opportunities for individuals within these organizations to make connections with each other and to agree to meet and work together in the interests of collaboration and cooperation for the overall good of the profession. This is not always an easy process: reconciling differences in training approaches, the duration of training and the required hours of clinical experience, produces many challenges. Nevertheless, it is vital for arts therapists to create an inclusive platform and one that provides mutual opportunities for professional development and cooperation. It is also essential that a unified profession be portrayed to the public, to other professions and to governments. Australia has an established 'Arts in Health' movement that has recently 
achieved a high degree of government support (see for example, Arts and Health Australia, 2015). Kapitan (2014) observes that there are thousands of arts projects going on all over the world with artists, activists, environmentalists, and relief workers using arts for healing and well-being. She argues that it is paramount that the arts therapy profession becomes more connected with this significant global movement.

Currently, there are many individuals within ANZATA who are working to establish links and build cooperative relationships with other organisations and disciplines (including advocacy and conducting research) in order to promote the profession. Placement opportunities for trainees on most of the ANZATA approved programs are varied. They include special schools, trauma counselling centres, community mental health, school counselling, child and adolescent mental health, medical hospitals, hospices, addiction services and prisons - to name a few. In spite of the difficulties of gaining greater recognition in the medical field to date, arts therapists in our region are continuously introducing the profession to new arenas.

Full-time permanent specialist arts therapy positions are still uncommon in Australia, New Zealand and Singapore. Professional ANZATA members are often employed under other titles such as counsellors, psychotherapists, alcohol and drug counsellors, case workers and so on. The majority of arts therapists working in Australia, New Zealand and Singapore have gained employment through being flexible - often creating positions from an internship placement, developing projects within the community and setting up in private practice (Westwood, 2012; Woodcock, 2012). Most arts therapists are employed in the health, mental health, education, special education and social/community sectors. Practitioners also need to continue to advocate for the profession as well as for their own individual practice. There is an on-going need for the education of other professionals about the value of arts therapy and a heightened perception of the high standard of specialised postgraduate training that is required for the professional level of ANZATA registration - training that is in line with the highest level of international standards.

\section{Challenges}

Significant challenges for the arts therapies in our countries include the small number of qualified practitioners, the overall lack of knowledge and awareness of the profession displayed by the general public, other professions and governments and a sense of isolation caused by the large geographical spread of our members. Additionally, Dunphy, Mullane and Jacobsson's review of the effectiveness of expressive therapies in Australia note the nascence of the profession with a consequent dearth of a research culture and lack of understanding about arts therapy $(2013$, p. 13). In a move to reduce the isolation of practitioners, ANZATA has encouraged the establishment of regional groups. It is also offering both grants for initial set-up and extra funds that can be applied for to enable groups to invite guests for dialogue and professional development opportunities. ANZATA has over ten regional groups already functioning and more that are developing. In the past year, ANZATA has also offered an annual contestable research grant to members in order to encourage the development and dissemination of research.

There has been a lack of consistent governmental regulation of the allied health professions in both Australia and New Zealand. ANZATA is investigating the best routes for 
members to become eligible for a national registration process that some professions already have - professions such as psychology and occupational therapy. Governments in Australia and New Zealand, however, consider organisations with memberships of our size too small to be considered for this in our own right. As a result, ANZATA is now creating dialogue with larger professional bodies in these countries which are in the process of applying for this status. The process of considering any more professions for national registration seems to have stalled in both countries at this time, so currently arts therapy remains in the category of 'self regulation' - a category which some argue creates more flexibility and less restriction for the profession (Tudor, 2013). Professional arts therapy practice within Singapore remains unregulated at this time and local arts therapists remain cognizant of any relevant developments with the allied health professionals.

ANZATA has however, had several significant successes. It has liaised with the Australian Health Services Union to create pay awards in the health departments of several states (Eisdell, Shiell, \& Westwood, 2007). The profession is now listed under the Australian/ New Zealand Standard Classification of Occupations (ANZSCO). Recently, the New Zealand Accident Compensation Corporation (ACC), a body which funds counsellors and psychotherapists to treat survivors of sexual trauma, approved ANZATA as a recognised professional organization which could provide services to ACC. In 2015, ANZATA became a member organisation of the Allied Health Professions Association (AHPA).

\section{Opportunities}

Opportunities for arts therapy research have gradually increased in the last decade. Each of the ANZATA-approved training programs offer masters-level research degrees, though very few offer doctoral qualifications. At present, the majority of arts therapists wishing to undertake further research conduct doctoral level studies within other disciplines. Since 2006, ANZATA has published an annual peer-reviewed journal - The Australian and New Zealand Journal of Arts Therapy (ANZJAT); this journal publishes high-quality research from a range of methodologies that are evidence-based, practicebased, and arts-based. Balatti and Fenner (2014) conducted an analysis of the articles published from the first edition of ANZJAT from 2006 up to 2011. They found a strong preference for qualitative studies in line with arts therapy literature in general and argue that, in order to gain increased cross-disciplinary credibility, the "way forward" may be to increase the range of research methods employed (including quantitative approaches) and to encourage more universities to make doctoral degree level studies available in arts therapy departments. The need to encourage more research and literature that addresses culturally sensitive practices specific to the Australasian context is highlightedas is the need to find more systematic ways to conduct and document research in order to become more aligned with other allied health disciplines.

Individualistic Western approaches to counseling and psychotherapy may seem alienating to clients who come from highly communal cultures (Kim, 2012; Seiuli, 2013; Webber, 2013). Kalmanowitz, Potash, and Chan (2012) observe that many Australasian art therapists have acknowledged the influence of Western cultural norms on art therapy practice; they claim that although Western approaches are varied, there are many commonalities which are based on Western value systems. "Art therapy as a Western practice 
is still guided by individualistic ideas such a self-expression, individual rights, and the art object as a personal statement" (Kalmanowitz, Potash \& Chan, 2012, p. 41).

Durie, a highly respected Maori psychiatrist, explains that the Maori people have a view of well-being that "does not easily translate into symptom clusters, syndromes or isolated behavior patterns...[depression and anxiety, for example, can be viewed]...as indicators that the balance between emotions, social relationships, spirituality and the body have become distorted" (2003, p. 48). In the Maori belief systems, health and well-being need to be viewed from an holistic stance; culture and identity are intrinsically linked to well-being and there is an integrated life concept that recognizes the inter-connectedness of all aspects of being (Turner, 2006). There are several models of Maori well-being that have now become integrated into general counseling and psychotherapy training and to arts therapy training in New Zealand.

According to theorists, these models have strong similarities to those in Asia (Kalmanowitz, Potash, \& Chan, 2012; Kim, 2012) and the Pacific (Seiuli, 2013; Webber, 2013). Linnell (2009, p. 25), for example, calls for Australian arts therapists to challenge Western and modern binary notions and hopes that art therapy can "contribute effective acts of reconciliation". Many recently trained Western arts therapists have been strongly influenced by Shaun McNiff's research of indigenous models that express how "...shamanic and indigenous healing traditions from throughout the world consistently define illness as a loss of soul and treatment as soul retrieval, an idea that applies beautifully to what we do today in art therapy" $(2012$, p. 16).

\section{Moving Forward}

During its evolution - and despite historic ideological conflicts - ANZATA has inexorably moved towards a greater inclusion of, co-operation with and expansion of its membership in order to promote the profession and to establish greater recognition of and opportunities for employment. It has also sought to establish stronger links and working relationships with other organisations in both our own countries and those of our close neighbours. The range of countries of delegates attending the ANZATA/ LASALLE research symposium in Singapore (2014) is an example of such growing links and reflects this strategy in action. As a result of globalisation, much of the world has become increasingly inter-connected and there is now considerable value in a mutual exchange - "...there is an increasing movement towards each other, learning from each other and integration of ideals, philosophies and practice..." (Kalmanowitz, Potash \& Chan, 2012, p. 27). Arts therapists in Australia, New Zealand and Singapore are now looking less to Europe and the United States and more increasingly towards our own geographical and cultural region of Asia Pacific. Vitally important opportunities for mutual learning and development are burgeoning in this part of the world.

"The best things happen when people from throughout the world and from vastly different backgrounds listen to each other, study their respective traditions and ideas, open themselves to communion and influence, and move beyond ideologies of separation to mutual influence and creation" (McNiff, 2012, p. 19). 
Opportunities such as this important Congress are highly significant in helping to create a strong cultural identity in this region and build on the chance to take the best of all worlds - Indigenous, Eastern and Western - to create our own fusions that work within our context and era. We will be enabled and empowered to respect and learn from each other in order to share our ideas and build effective ways of working.

\section{About the Authors}

Joanne Kelly, PhD, MMH (Art Therapy), BEd (Hons), CertHlthProm, AThR, ACA, McAuley Catholic College, president@anzata.org. Jo Kelly is president of ANZATA. She completed her PhD in Education in the field of art therapy in high schools. Jo has worked in a range of therapeutic positions including disability, psychiatric in-patient and palliative care across age ranges but especially with children and young people. Prior to training as an art therapist, Jo worked in education, health promotion and the probation service. She has lived in North East India, Papua New Guinea and Bangladesh.

Amanda Levey MA AT, BA (Hons) Psych, AThR (ANZATA) Head of Department, Master of Arts in Arts Therapy, Whitecliffe College of Arts and Design, Auckland, AmandaL@whitecliffe.ac.nz Amanda Levey studied psychology at the University of Melbourne, Australia, then undertook further training in the USA. She gained her MA in arts therapy at Whitecliffe College of Arts and Design in Auckland, New Zealand, and is the Programme Director there. Amanda is the current secretary of the Australian and New Zealand Arts Therapy Association (ANZATA). Her research interests are in dance/ movement therapy, performative video, movement in the natural environment and duo-ethnography.

Ronald PMH Lay MA, AThR, ATR-BC, Programme Leader, MA Art Therapy School of Creative Industries, Faculty of Fine Arts, Media \& Creative Industries, LASALLE College of the Arts, Singapore. Ronald.lay@lasalle.edu.sg Ronald has extensive mental health service provision experience spanning over 25 years in Canada, USA and Singapore. He is the Program Leader of the MA Art Therapy Program at LASALLE College of the Arts. He has an emerging research agenda that complements his practitioner and academic approach. He presents internationally on art therapy, forensic mental health, adults and art therapy in Asia. He is currently pursuing his Doctorate in Education.

\section{Conflicts of Interest}

The authors declare no conflict of interest.

\section{References}

Agee, M N, McIntosh, T, Culbertson, P, \& Makasiale, C O (Eds.). (2013). Pacific identities and wellbeing: cross cultural perspectives (pp. 103-114). Dunedin, New Zealand: Otago University Press. Dunedin, New Zealand: Otago University Press.

Aun Long, J, \& Tan, D. (2012). The growth of the private wealth management industry in Singapore and Hong Kong. Capital Markets Law Journal, 6(1), 104-126. doi: 10.1093/cmlj/kmq022.

Arts and Health Australia. (2015). Retrieved 23 April, 2015, from http://www.artsandhealth.org.au/ about-us/advisory-committee.html 
Balatti, N, \& Fenner, P. (2014). Taking a closer look: A review of ANZJAT publications 2006-2011. Australian and New Zealand Journal of Art Therapy, 9(1), 15-28.

Cane, S. (2013). First Footprints - the epic story of the first Australians. Crows Nest Australia: Allen \& Unwin.

CIA. (2015). The World Factbook: South East Asia: Singapore. Retrieved 22 April, 2015, from https:// http://www.cia.gov/library/publications/the-world-factbook/geos/sn.html

Coulter, A M. (2006). Art Therapy in Australia: The Extended Family. Australian and New Zealand Journal of Art Therapy, 1(1), 8-18.

Dorey, F. (2011). "The spread of people to Australia”. Retrieved 22April, 2015, from http://australianmuseum.net.au/the-spread-of-people-to-australia

Dunphy, K, Mullane, S, \& Jacobsson, M. (2013). The effectiveness of expressive arts therapies: A review of the literature. Melbourne: PACFA.

Durie, M. (2003). Durie, M. (2003). Ngā Kāhui Pou: Launching Māori futures. Wellington, New Zealand: Huia Publishers.

Eisdell, N, Shiell, M, \& Westwood, J. (2007). Health services union: work value submission, art therapy profession: Australia \& New Zealand Art therapy Association Inc.

Essame, C. (2012). Collective versus individual societies and the impact of Asian values on art therapy in Singapore. In D. Kalmanowitz, J. S. Potash \& S. M. Chan (Eds.), Art therapy in Asia: To the bone or wrapped in silk (pp. 91-101). London, UK: Jessica Kingsley.

Gilroy, A, \& Hanna, M. (1998). Conflict and Culture in Art Therapy; An Australian Perspective. In A Hiscox \& A. Calish (Eds.), Tapestry of Cultural Issues in Art Therapy (pp. 249-275). London, UK: Jessica Kingsley Publishers.

Halprin, A. (2000). Dance as a healing art: Returning to health through movement \& imagery. Medicino, CA: LifeRhythm.

Halprin, D. (2003). The expressive body in life, art and therapy: Working with movement, metaphor and meaning. London, UK: Jessica Kingsley Publishers.

History Group of the New Zealand Ministry for Culture and Heritage. (2015). Treaty of Waitangi. Retrieved 22 April, 2015, from http://www.nzhistory.net.nz/politics/treaty-of-waitangi

Kalmanowitz, D, Potash, J S, \& Chan, S M. (2012). Introduction. In D. Kalmanowitz, J. S. Potash \& S. M. Chan (Eds.), Art therapy in Asia: to the bone or wrapped in silk. London, UK: Jessican Kingsley Publishers.

Kapitan, L. (2014). Re: Invention and realignments of art therapy. ATOL Art Therapy Online, 5(1), 1-21.

Kaplan, F F. (2005). Art, Science and Art Therapy. Repainting the Picture. London and Philadephia: Jessica Kingsley Publishers.

Kim, S Y. (2012). Towards and integrated medicine. In D. Kalmanowitz, J. S. Potash \& S. M. Chan (Eds.), Art therapy in Asia: To the bone or wrapped in silk (pp. 78-88). London, UK: Jessica Kingsley Publishers.

Linnell, S. (2009). Becoming 'Otherwise': A Story of a Collaborative and Narrative Approach to Art Therapy with Indigenous Kids 'in care'. Australian and New Zealand Journal of Art Therapy, 4(1), $15-26$

McNiff, S. (2004). Art Heals. How Creativity Cures the Soul. Boston: Shambala, USA.

McNiff, S. (2012). Foreward. In D. Kalmanowitz, J. S. Potash \& S. M. Chan (Eds.), Art therapy in Asia: To the bone or wrapped in silk (pp. 13-20). London, UK: Jessican Kingsley Publishers.

Payne, H (Ed.). (1992). Dance movement therapy: Theory and practice. London, UK: Routledge.

Seiuli, B M S. (2013). The meaalofa therapeutic approach to counselling with Pacific clients. In M. N. Agee, T. McIntosh, P. Culbertson \& C. O. Makasiale (Eds.), Pacific identities and well-being: Cross cultural perspectives (pp. 103-114). Dunedin, New Zealand: Otago University Press. 
Stoll, B. (2005). Growing pains: The international development of art therapy. The Arts in Psychotherapy, 32, 171-191.

Tudor, K. (2013). "Be careful what you wish for": Professional recognition, the statutory regulations of counselling and the state registration of counsellors. New Zealand Journal of Counselling, 33(2), 46-69.

Turner, S. (2006). Maori worldview and art as therapy. Unpublished Masters dissertation. Whitecliffe College of Arts and Design. Auckland.

Webber, M. (2013). Adolescent racial-ethnic identity: Behaviours, perceptions and challenges in urban multi-ethnic school contexts. In M. N. Agee, T. McIntosh, P. Culbertson \& C. O. Makasiale (Eds.), Pacific identities and well-being: Cross-cultural perspectives (pp. 5-26). Dunedin, New Zealand: Otago University Press.

Westwood, J. (2012). Hybrid creatures: Mapping the emerging shape of art therapy education in Australia, including reflections on New Zealand and Singapore. Australian and New Zealand Journal of Arts Therapy, 7(1), 15-25.

Westwood, J, \& Linnell, S. (2011). The emergence of Australian art therapies. Art Therapy Online: ATOL, 1(3), 1-19.

Woodcock, M. (2007). A viewpoint and reflections on the devleopment of art therapy in New Zealand. Australian and New Zealand Journal of Art Therapy, 2(1), 8-20.

Woodcock, M. (2011). Art Therapy in Aotearoa/New Zealand. Art Therapy Online: ATOL, 1(3). 